\title{
DSGE models and their use at the ECB
}

\author{
Frank Smets • Kai Christoffel • Günter Coenen • \\ Roberto Motto - Massimo Rostagno
}

Received: 16 October 2009 / Accepted: 09 December 2009 / Published online: 23 February 2010

C The Author(s) 2010. This article is published with open access at Springerlink.com

\begin{abstract}
Bayesian dynamic stochastic general equilibrium (DSGE) models combine microeconomic behavioural foundations with a full-system Bayesian likelihood estimation approach using key macro-economic variables. Because of the usefulness of this class of models for addressing questions regarding the impact and consequences of alternative monetary policies they are nowadays widely used for forecasting and policy analysis at central banks and other institutions. In this paper we provide a brief description of the two main aggregate euro area models at the ECB. Both models share a common core but their detailed specification differs reflecting their specific focus and use. The New Area Wide Model (NAWM) has a more elaborate international block, which is useful for conditioning the euro area projections on assumptions about foreign economic activity, prices and interest rates and to widen the scope for scenario analysis. The Christiano, Motto and Rostagno (CMR) model instead has a more developed financial sector, which allows it to be used for monetary and financial scenarios and for cross checking. Based on the comparison of two models we find a broad agreement on the qualitative predictions they make, although, in quantitative terms, there are some differences. However, the perspectives provided by the two models are often complementary, rather than conflicting.
\end{abstract}

Keywords DSGE models · Central banks · Monetary policy

JEL Classification $\mathrm{B} 4 \cdot \mathrm{C} 5 \cdot \mathrm{E} 32 \cdot \mathrm{E} 50$

Prepared for a special issue of the Spanish Economic Review. The opinions expressed are our own and should not be attributed to the European Central Bank or its Governing Council.

F. Smets $(\varangle) \cdot$ K. Christoffel · G. Coenen · R. Motto · M. Rostagno

European Central Bank, Frankfurt, Germany

e-mail: Frank.Smets@ecb.int 


\section{Introduction}

Central banks need a wide range of macro-econometric models and tools for forecasting and monetary policy analysis. Over the past 5 years, an increasing number of institutions have introduced Bayesian dynamic stochastic general equilibrium (DSGE) models in their tool kit for policy analysis. ${ }^{1}$ These models combine a consistent, microfounded DSGE structure, characterised by the derivation of behavioural relationships from the optimising behaviour of agents subject to technological and budget constraints and the specification of a well-defined general equilibrium, with a full-system Bayesian likelihood estimation using key macro-economic variables.

As argued by Smets and Wouters (2003, 2004), the DSGE approach is particularly suitable for addressing questions regarding the impact and consequences of alternative monetary policies. The general equilibrium structure lends itself to telling economically coherent stories and structuring forecast-related discussions around it. Off-model information about "deep" structural parameters can be used to calibrate and/or estimate the model, which is particularly useful when time series are short. The model structure also helps to identify parameters and the type of shocks hitting the economy and to reduce the risk of over-fitting. Finally, the structural nature of the model and, in particular, its explicit account for the role of expectations makes the analysis less subject to the Lucas critique and more suitable for policy analysis. DSGE models put a premium on the important role of expectations in assessing alternative policy actions. They also give a better feel for which parameters are likely to be policy invariant and which ones are not.

The empirical strategy, full-system Bayesian likelihood estimation, also has a number of advantages over the more traditional equation-by-equation estimation of large macro models. First, it formalises the use of prior information and helps identification, thereby making the estimation algorithm of the highly restricted and non-linear model much more stable. As shown by Canova (this issue), the likelihood function of DSGE models is often flat and irregular in a number of the parameters. Prior information helps overcoming such identification issues. Secondly, the Bayesian likelihood approach delivers a full characterisation of the parameter and shock uncertainty, allowing easily constructing probability distributions for unobserved variables (e.g. the output gap) and derived functions (e.g. forecasts). The state-space formulation underlying the approach, whereby the state equation captures the dynamics of the state variables in the model economy and the observation equations links those state variables to observable macro-economic time series, is a very flexible tool that can deal explicitly with measurement error, unobservable state variables, large data sets and different sources of information. Finally, the Bayesian estimation methodology provides a natural framework for decision making under uncertainty. As new data and new models appear, decision makers can update their posterior probabilities and appropriately weigh them when making decisions.

The attractive combination of rigorous economic reasoning and data coherence that characterises Bayesian DSGE models implies that they can be used successfully for

\footnotetext{
1 Examples are the Sveriges Riksbank, the Norges Bank, the Czech National Bank, the Federal Reserve Board, the IMF and the European Commission.
} 
scenario analysis and monetary policy design without compromising on their forecasting performance, which is comparable to the one of purely statistical and data-driven methods. In this paper, we provide a brief description of the two main aggregate euro area DSGE models that are being used in the context of the ECB's quarterly projection rounds and the associated cross-checking in the context of the ECB's monetary analysis. Both models have a core which is similar to that of Christiano et al. (2005) and Smets and Wouters (2003). However, the New Area Wide Model (NAWM) has a more elaborate international block, which is useful for conditioning the euro area projections on assumptions about foreign economic activity, prices and interest rates. The Christiano, Motto and Rostagno (CMR) model instead has a more developed financial sector, which allows it to be used in cross checking. In addition to the two estimated euro area DSGE models, a number of other DSGE models have been developed to address specific issues such as the effects of fiscal policy, the international interactions between the euro area and the rest of the world and country-specific developments within the euro area. ${ }^{2}$ These are not discussed in this paper.

The rest of the paper is structured as follows. Section 2 gives a brief description of the main features of those two models and their use at the ECB. Section 3 compares some of the empirical and structural features of the two models. First, it discusses and compares the monetary policy transmission mechanism in both models. Secondly, it uses the models to interpret the sources of recent developments in economic activity in the euro area. Finally, it provides an example of the counterfactual policy simulations that can be done using the two models. More details and examples of this type of empirical, quantitative policy analysis can be found in the various papers describing the two models and their applications. Finally, the last section (Sect. 4) briefly addresses some of the recent criticism of modern DSGE models that has arisen in the light of the current financial crisis and provides some conclusions.

\section{Estimated euro area DSGE models at the ECB}

Many models are in use at the ECB ranging from purely statistical models to fully fledged structural (DSGE) models. Within the class of DSGE models, two models are routinely used in the policy process. The NAWM has been developed for forecasting purposes and for policy analysis. The CMR model has been developed to support the monetary analysis of the ECB and its two-pillar strategy, and to conduct monetary and financial scenarios. The need to serve for different purposes has driven also the modelling choices in developing these models. The NAWM includes a detailed international block, whereas the CMR includes a detailed modelling of the monetary and financial side of the economy.

The two models share similar long-run properties and a similar "core block". This lends itself to interpreting the specificities of the two models in terms of additional transmission channels with respect to their common "core block". The core model

\footnotetext{
2 These models include the version of the NAWM used for globalization studies (Jacquinot and Straub 2008), the NAWM with a financial block (McAdam and Lombardo (2009)), a DSGE model to analyse macroeconomic interdependencies in the euro area (Gomes et al. 2009) and the rational expectation multi country model for the euro area countries used for forecasting and policy analysis (Dieppe et al. 2009).
} 


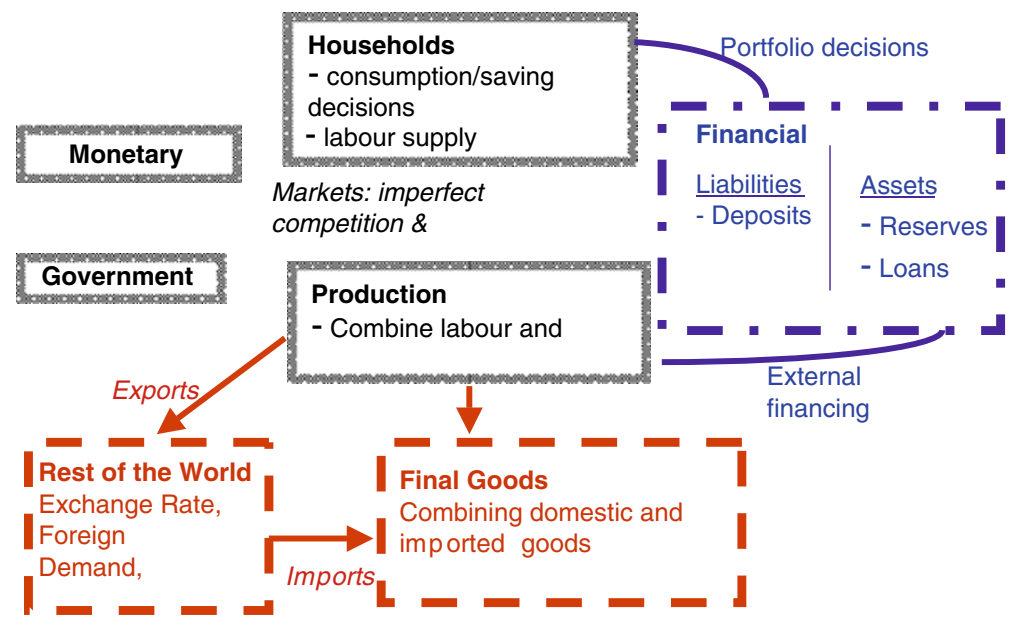

Fig. 1 Structure of the Models. Note: The boxes with the solid frame denote the core model that is nested in both models. The boxes with dashed frame at the bottom of the figure show the open economy features of the NAWM whereas the box with dash-dotted frame on the right-hand side of the figure describes the financial dimension modelled in the CMR

includes features introduced in Christiano et al. (2005) and Smets and Wouters (2003), which have been shown to help explaining the data well both in the US and the euro area. Such features have become standard in DSGE modelling. They include habit persistence in consumption, adjustment costs in the flow of investment, imperfect competition, sticky prices and sticky wages, and the inclusion of a large number of structural shocks that act as shifters of the structural relationships. Figure 1 provides a diagrammatic representation of the main sectors of the economy included in the "core block" (boxes with solid frame in the middle of the figure) and of the additional sectors that are included in the NAWM (boxes with dashed frame at the bottom of the figure) and the CMR model (box shaded with dashed-dotted frame on the right-hand side of the figure).

In the NAWM the common core block is embedded into an international environment. ${ }^{3}$ This has wide-ranging consequences for the model dynamics both regarding the influence of foreign developments on the domestic economy as well as by directly influencing the decision process of domestic households and firms.

Households are trading both domestic and foreign bonds. The effective return on the risk-less domestic bonds depends on a financial intermediation premium, which drives a wedge between the interest rate controlled by the monetary authority and the return required by the household. Similarly, when taking a position in the international bond market, the household encounters an external financial intermediation premium which depends on the economy-wide (net) holdings of internationally traded foreign bonds expressed in domestic currency relative to domestic nominal output. That is, if the domestic economy is a net debtor, households have to pay an increasing external

\footnotetext{
3 See Christoffel et al. (2008) for a full description of the NAWM model.
} 
intermediation premium on their international debt. The uncovered interest parity condition determines the dynamics of the exchange rate.

Turning to the production side there are four different kinds of firms. In the production sector of the tradable, intermediate good there are domestic firms producing for the domestic market, domestic firms producing for the foreign market and foreign firms producing for the domestic market. The intermediate good firms engage in Calvo price setting where both import as well as export goods are priced in the domestic currency. ${ }^{4}$ The representative firm producing the non-tradable final investment and private consumption goods, combines purchases of a bundle of domestically produced intermediate goods, with purchases of a bundle of imported foreign intermediate goods. The relative demand for the goods is determined by the relative prices, the price elasticities and the degree of home bias. The resulting trade flows are affected by domestic and foreign demand, relative prices and by the exchange rate, accounting for limited exchange-rate pass-through in the short to medium run.

The design of the NAWM for use in the ECB/Eurosystem staff projections has been guided by two important considerations, namely (i) to provide a comprehensive set of core projection variables and (ii) to allow conditioning on monetary, fiscal and external developments which, in the form of technical assumptions, are an important element of the projections. As a consequence, the scale of the model-compared with a typical DSGE model-is relatively large. Employing Bayesian methods, it is estimated on 18 key macroeconomic variables. In addition to standard national account data, data for the nominal effective exchange rate, euro area foreign demand, euro area competitors' export prices as well as oil prices are used, which are deemed important variables in the projections capturing the influence of external developments.

Turning to the CMR model, it extends the "core block" by explicitly modelling the monetary and financial dimension of the economy. Portfolio and financing decisions are non-recursive in the model, but they directly affect consumption, investment and prices. The model is a variant of the model with financial frictions developed in Christiano et al. $(2003,2007)$, which in turn includes the financial accelerator of Bernanke et al. (1999) and the banking system of Chari et al. (1995). The main features of financial intermediation in the CMR are the following. First, the presence of many types of assets in the economy that differ in their degree of liquidity and maturity gives rise to portfolio decisions. Second, investment in physical capital is leveraged, giving rise to the need for external financing. There is risk of default; and the presence of asymmetric information in credit markets implies that the incentives of borrowers and lenders are not aligned. This leads the lender to charge a premium which is a function of the equity of the borrower. As the value of equity is mainly driven by asset price fluctuations, there is a direct link between asset prices and real economic activity. Third, in the model part of the working capital has to be financed prior to the time in which revenues from selling current production become available. Fourth, in the model savers and lenders do not interact directly but via financial intermediaries. Intermediaries have their own balance sheet with liabilities, mainly different type of deposits, so that it is possible to construct aggregates

\footnotetext{
4 The alternative setting, assuming local currency pricing both for exports and imports, leads to counterfactual production price dynamics in the eurozone and a deteriorated fit of the model in the estimation.
} 

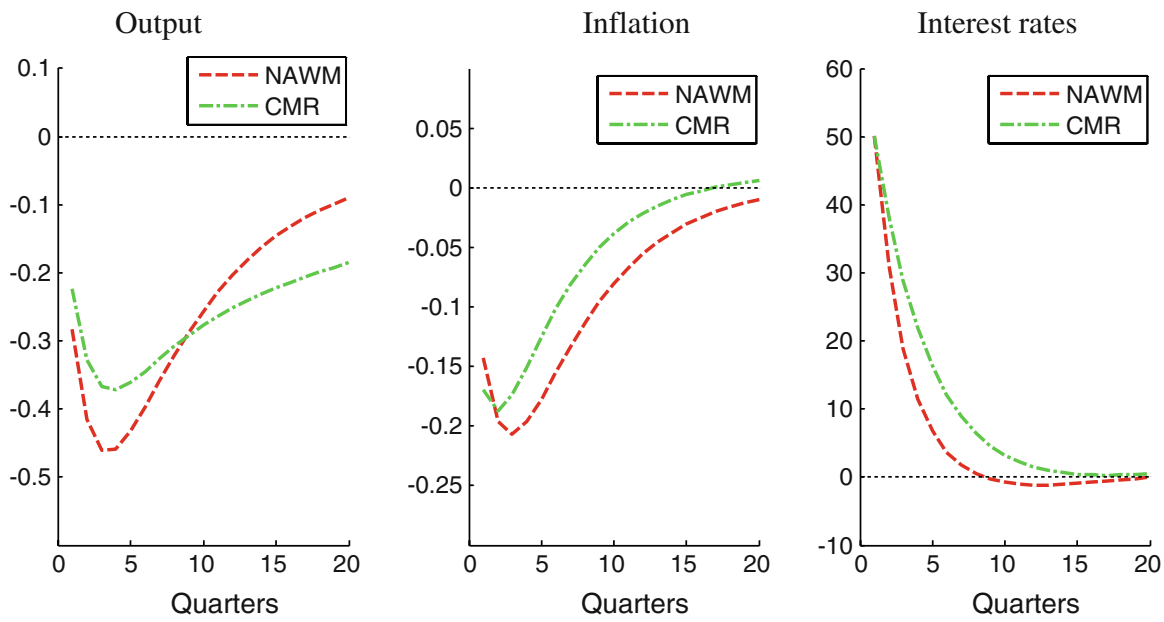

Fig. 2 Monetary policy transmission mechanism. Note: The dashed and dash-doted lines show the response of the NAWM and the CMR model to an unanticipated 50 basis point increase in interest rates, for output annualized inflation and interest rates

such as M1 and M3, and assets, mainly, different types of loans. The production of deposits requires resources in terms of capital, labour and excess reserves. The presence of excess reserves captures the intermediaries' need for maintaining a liquidity buffer to accommodate unexpected withdrawals. In the model intermediaries cannot default. Finally, in the model financial contracts are denominated in nominal terms. As borrowers and lenders are ultimately interested in the real value of their claims, shifts in the price level unforeseen at the time the financial contract is signed bring about real effects. This is a way to include the "Fisher debt-deflation" channel in the model.

The parameter values underlying the quantitative results presented in the remaining of the paper are obtained in two ways. Some structural parameters are calibrated in order to match great-ratios and long-run averages. In the calibration it is ensured that the long-term properties of the two models coincide to the largest possible extent. The remaining structural parameters and the parameters governing the stochastic processes are estimated by using a Bayesian version of the standard maximum likelihood approach.

\section{A comparison of the NAWM and the CMR models}

\subsection{Monetary policy transmission mechanism}

In this section we assess the dynamic implications of the models by comparing the transmission mechanism of monetary policy shocks. Figure 2 shows the response to an unexpected increase in the nominal interest rate of 50 basis points.

As the two models share some of the transmission channels, we focus on the role played by the channels which are specific to each of the models. 
In line with common wisdom regarding the transmission of monetary policy, in the NAWM the increase in the real rate leads to temporarily curtailed demand, with investment falling more strongly than consumption. The responses reflect also the open economy dimension and the endogenous response of the exchange rate adding additional transmission channels affecting both the real and nominal side.

On the real side we find that the positive interest rate differential between foreign and domestic bonds implies an increased demand for domestic bonds. This implies an appreciation of the domestic currency via the uncovered interest parity assumption. Since intermediate imports are priced in the local currency the exchange rate movement implies a gradual, but noticeable drop in import prices and an improvement of the terms of trade. The improved terms of trade lead to expenditure-switching from domestic towards foreign goods in the composition of the final consumption and investment goods. As a consequence, imports fall by less than domestic demand. Exports are priced in producer currency implying a stronger price increase and a more pronounced reduction in exports.

Continuing with the price side reaction to a monetary policy shock we find two additional effects of the open economy dimension. First and as discussed above, the open economy features imply an amplification of the decline in aggregate demand and consequently in factor demand. Firms cut back their demand for labour and, therefore, employment falls. Via its impact on firms' marginal cost, the resulting decline in wages puts downward pressure on domestic prices. Second, consumption prices will decline more strongly than domestic prices because of the drop in import prices due to the appreciation of the domestic currency. In sum, the peak absolute effect on economic activity and inflation is reached after about 1 year, whereas the implied price level effects are gradual and long-lasting.

Turning to the CMR model, the asset side of the financial sector's balance sheet introduces three main propagation mechanisms relative to the "core block". First, there is the financial accelerator effect. The deterioration in economic activity brought about by the initial monetary policy tightening leads to a shortfall in earnings and to capital losses, both of which erode the value of borrowers' net worth. The associate rise in the bankruptcy rate leads to a rise in the external finance premium charged over and above the risk-free rate controlled by the central bank. This channel tends to magnify the contractionary impact of a policy tightening. The second propagation mechanism, the "Fisher debt-deflation" channel reinforces the standard accelerator effect described above. The debt-deflation effect implies that the decline in the price level brought about by the unexpected increase in the policy rate-thus by construction also the decline in the price level is unforeseen at the time the financial contract was signed-increases the real value of the debt outstanding. This redistribution of wealth between borrowers and lenders has real effects on the economy. Note that the Fisher and accelerator mechanisms reinforce each other only in the case of shocks that move the price level and output in the same direction, such as monetary policy shocks, whereas they tend to cancel each other out in the wake of shocks that move the price level and output in opposite directions, such as transitory technology shocks. The third propagation mechanism in the model is given by the need to finance part of the working capital in advance. The additional propagation mechanisms included in the model should not be taken as necessarily implying stronger downward pressure on 
inflation. On the one hand, higher financing costs lead to lower inflationary pressure via their depressing effect on economic activity. On the other hand, they represent additional costs, putting upward pressure on price developments.

The model makes also predictions for the liability side of banks' balance sheet. Given the importance of monetary and credit developments in the ECB monetary policy strategy, understanding the path followed by narrow and broad monetary aggregates in response to a policy tightening is of particular interest. According to the model, a policy tightening triggers an initial positive reaction of the stock of nominal M3. This is driven by the speculative demand for money, captured by the M3 components outside M1. This is explained by the fact that the interest rate earned on instruments included in M3-M1 is closely linked to market rates. The model suggests that the own rate on M3-M1 goes up approximately by the full 50 basis points rise in the policy rate. The interest rate earned on the liquid component of M3 is instead less reactive. According to the model, after the initial rise, M3 undergoes a significant and permanent decline. This "perverse" initial decline of M3 following a policy tightening found in the model is consistent with evidence obtained on the basis of identified VARs.

Overall, taking into account that the two models share only some of the transmission channels, the quantitative differences between the NAWM and the CMR responses to a policy shock appear to be rather small.

\subsection{Structural interpretation of GDP growth}

The models can be used to interpret recent macroeconomic developments in terms of the structural shocks that have hit the economy. The results of this are displayed in Figs. 3 and 4, which provide an additive decomposition of annual GDP growth. The contribution of the different categories of shocks is shown by means of bars of different colour. Looking at the different phases of the business cycle since the start of the European Monetary Union (EMU) in 1999, the main findings are the following.

First, both models suggest that the expansion of 1999-early 2000 is mainly explained in terms of forces that can be probably associated with the convergence process in interest rates in the run-up to EMU (see light blue bars with diagonal lines), and in terms of increased degree of competition, possibly driven by globalisation forces (see green bars, color figure online). Demand shocks are found to be lagging (see red bars with diamonds).

Second, the interpretation of the slowdown of 2000-2001 and the following phase of weak growth until 2005 provided by the two models is less clear cut. The NAWM suggests that the downturn starting in the second half of 2000 was triggered by adverse influences from abroad. For instance, the emergence of new competitors in euro area export markets eventually led to losses in export market shares. Moreover, the sharp deceleration of economic activity in the United States and its spillovers to the rest of the world caused a pronounced fall in euro area foreign demand from 2001 onwards. Within the NAWM, these developments are captured by negative export preference and negative foreign demand shocks, respectively. Furthermore we can observe a negative contribution of the technology shock group in the 2001 slowdown. Looking at the further decomposition we can attribute this mainly to the transitory technology 


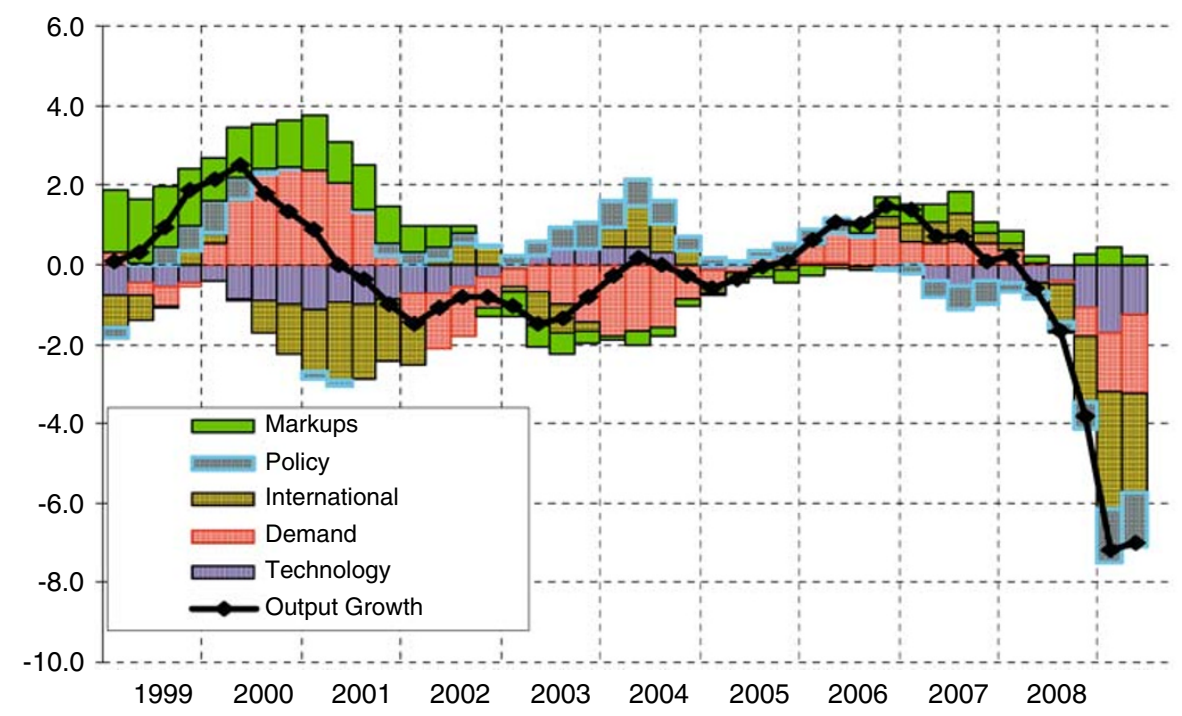

Fig. 3 Structural interpretation of GDP growth in NAWM. Note: GDP growth, year-on-year \% change, in deviation from mean. Last observation is $2009 \mathrm{q} 2$

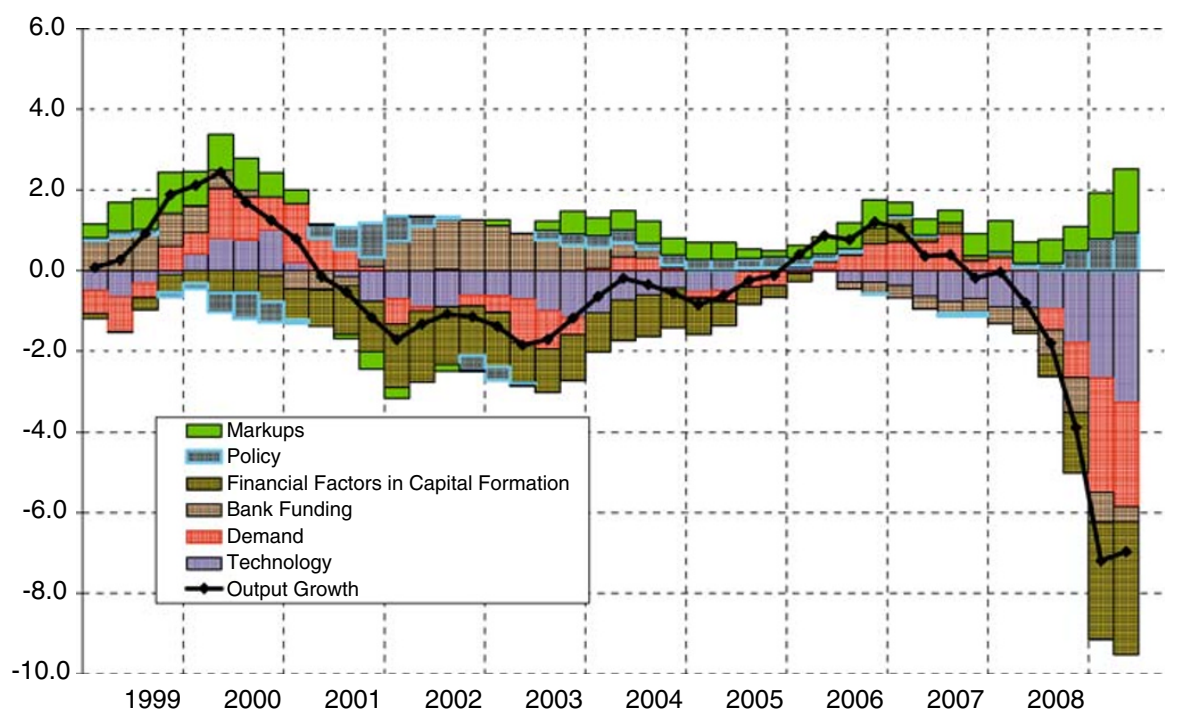

Fig. 4 Structural Interpretation of GDP growth in CMR. Note: GDP growth, year-on-year \% change, in deviation from mean. Last observation is $2009 \mathrm{q} 2$

shock which is related to the increased degree of labour hoarding in this episode. The subdued growth of real GDP over the period 2002-2005 is then largely explained by negative demand shocks, notably domestic risk premium shocks, that entailed a protracted slump in domestic spending. Since 2003 the overall contribution of the foreign shocks has been rather modest. This masks the fact that in 2003 the adverse impact of external risk premium shocks (accounting for the marked appreciation of 
the euro) was largely offset by the unwinding of the previous shocks to export preferences. In contrast, the favourable developments in euro area foreign demand during the 2004-2006 period have been largely compensated by the continued appreciation of the euro and a renewed deterioration of foreign preferences for euro area exports.

The CMR model suggests a different interpretation of the rapid slowdown of 20002001. It does not support the occurrence of adverse technological shocks and explains this episode in terms of negative financial factors associated with the stock market collapse. Financial shocks mainly capture the sudden re-appraisal of profit prospects, which led to the stock market collapse, which in turn aggravated the already weak balance-sheet position of the corporate sector at the time. The associated rise in the riskiness of lending activity led to a sharp rise in the external finance premium. This prompted a cut in investment plans and a painful process aimed at repairing balance sheets. According to the model, financial shocks exerted a progressively stronger downward pull on output until the end of 2002 and then they started receding. As of 2002, the poor economic performance is explained by the CMR also in terms of unfavourable productivity shocks which exerted a downward pull on economic activity and upward pressure on inflation. This countercyclical behaviour of productivity shocks had clear monetary policy implications, as it prevented inflation from quickly receding, notwithstanding the decline in resource utilisation caused by the economic slowdown.

Third, both models (although the CMR to a larger extent) find that monetary policy was instrumental in preventing the unfavourable forces that hit the euro area over the period from 2001 to 2006 from causing a more severe slowdown.

Fourth, both models find that the recovery initiated at the end of 2005 is different in nature to the earlier recovery in 1999, and is mainly a demand driven phenomenon.

Turning to the recent recession and to the impact of the financial crisis on GDP growth the NAWM explains the downturn in terms of three mayor components. First, the financial turmoil led to an increase in perceived financial risks and higher risk premia in terms of the spread between market interest rates and the rates controlled by the monetary authorities. The increased risk premium depressed domestic demand components as captured in the red bars with diamonds. Second, the deterioration of the supply side led to a downward revision of production capabilities as measured in the negative contribution from the technology shock group. Third and most importantly, the global dimension of the crisis implied a substantial reduction in world trade and a corresponding plummeting of exports in the euro area. This effect is particularly important because the reduction in world trade was accompanied by losses in market shares owing to the high proportion of investment goods in euro area exports. The negative contribution of the monetary policy group includes the shock to the simple, empirical monetary policy rule, but not the non-conventional monetary policy measures installed in response to the crisis.

According to the CMR, the most important driver of the recent crisis can be traced down to shocks emanating from financial intermediation (see yellow bars with horizontal lines), in particular the sudden re-appreciation of credit risk. The second most important contribution to the recent free fall in real economic activity has been the sharp drop in domestic and international demand (see red bars with diamonds). In 
Table 1 Counterfactual scenario

\begin{tabular}{lllr}
\hline & 2005 & 2006 & 2007 \\
\hline NAWM & 0 & 30 & 52 \\
$\quad$ Inflation & 3 & 20 & 11 \\
GDP growth & & & 34 \\
CMR & 0 & 17 & 8 \\
Inflation & 2 & 16 & \\
GDP growth & 0 & & \\
\hline
\end{tabular}

Average difference between counterfactual outcome and historical data over a given year. Inflation is measured in terms of the GDP deflator, and expressed in year-on-year terms. GDP growth is in quarter-on-quarter terms

Difference with respect to historical data (in basis points)

addition, according to the model, the situation has been aggravated by the deterioration of the supply side of the economy (see blue bars with vertical lines). The only positive support to the economy has come from the exceptional compression of markups, and from monetary policy (see light blue bars with diagonal lines) associated with the unprecedented slashing of policy rates.

\subsection{A policy counterfactual}

As an example for a policy counterfactual, we assess the macroeconomic impact of delaying the policy tightening cycle that started in 2005. At that time the policy rate was maintained constant at $2 \%$ since 2001 , due to protracted weak economic activity and subdued inflation. On the basis of its assessment of the inflation outlook, in December 2005 the ECB decided to start removing policy accommodation with a series of interest rate hikes. This decision was criticised at the time by several commentators and politicians on the basis that it started too early and the tightening cycle should have been postponed by a few quarters. The models can be used to answer the question, what would have happened to economic activity and inflation if the interest-rate cycle was delayed by, say, two quarters?

As shown in Table 1, delaying the interest rate cycle would have shifted inflation upward significantly, reaching the peak effect almost 2 years later. In 2007 actual inflation turned out to be $2.4 \%$, considerably above the ECB definition of price stability of close but below 2\%. Had the ECB delayed its tightening cycle, in 2007 inflation would have been 34 basis points higher according to the counterfactual simulation carried out with the CMR model, and 52 basis points higher according to the NAWM. Table 1 shows that the impact on economic activity arising from delaying the tightening cycle would have been felt especially in 2006, with GDP growth higher by 16 basis points according to the CMR and 20 basis points higher according to the NAWM.

\section{Recent criticism of the DSGE approach}

The introduction of Bayesian DSGE models in policy institutions has also been accompanied by increasing criticism of some of the elements and assumptions underlying this approach. In this section, we briefly address three of those criticisms. 
First, it has been argued that both econometrically and economically some of the shocks and frictions in common DSGE models are not well identified. The most forceful illustration of these identification problems in standard New Keynesian models has been provided by Canova and Sala (2009). These authors and Canova (this issue) show that the likelihood function often shows little curvature in key parameters of the model. Moreover, because of the highly non-linear nature, it is not always obvious where the identification problems lie, making correct inference difficult. Clearly, acknowledging these identification problems must be an important element of any empirical analysis. However, as argued above, the Bayesian approach allows using prior information to address some of these identification problems. For example, Mackowiak and Smets (2009) discuss how the wealth of new micro information on price setting can be used in the specification and estimation of macro models. Clearly, there is never an unambiguous, one-to-one mapping between micro features such as the frequency of price changes and the simplified structural macro model. However, confronting micro information with its macro-implications is a useful and informative exercise which can help reduce identification problems. It can also point to deficiencies in the specification of the model. Similarly, as shown above it is standard practice to calibrate some of the key parameters by using, for example, information on the great macro-economic ratios. The analysis of Canova and Sala (2009) does highlight that it is important to check the informativeness of the data by comparing the prior distribution with the posterior distribution. One of the criticisms of Chari et al. (2008) of the Smets and Wouters (2007) model is that the economic interpretation of some of the shocks is not clear. For example, the so-called wage mark-up shocks affecting the labour supply equation could be due to a variety of factors such as shifts in labour supply coming from changing preferences or participation rates, shifts in the bargaining power of unions or changing taxes. The welfare and policy implications of these different sources of wage mark-up variations can be quite different. Also in this case, using additional information may help solving this identification problem. For example, Gali (2009) shows that simply adding the unemployment rate to the observable variables may allow distinguishing between the first two sources of mark-up fluctuations.

Second, the assumption of rational (or model-consistent) expectations and perfect information, which underlies most of the DSGE models, is obviously an extreme assumption. As argued above, it is a useful and consistent benchmark, in particular when analysing the steady-state effects of changes in the policy regime. By bringing out expectations explicitly, their impact can be discussed directly. At the same time, it is unreasonable to assume that in an uncertain world and taking into account that the model is an abstraction of reality agents use the model to form their expectations in a model-consistent way. A number of avenues have been pursued to include learning and imperfect information in DSGE models. First, it is fair to say that addressing information problems at the micro level and analysing its implications for the aggregate macro economy is still at an early stage and is only feasible in small highly stylised models. Second, a number of authors have introduced learning about shocks in the model. This will typically help explaining some of the persistence in the response of the economy to shocks. For example, Collard et al. (2009) show that models with such signal extraction problems better fit the data. Third, an alternative is to endow the agents with forecasting regressions that are regularly updated. Milani (2006, 2008) 
and Slobodyan and Wouters (2009) find that DSGE models with learning mechanisms of this sort fit the macro-economic variables better than rational-expectations models and can also explain some of the time variation in the estimated persistence of inflation and variances.

A third criticism has become loud and clear since the outbreak of the financial crisis. Most DSGE models do not explicitly model a financial intermediation sector and rely on perfect arbitrage equations to model asset prices. As a result, there is only a limited role for financial phenomena such as agency problems arising from asymmetric information giving rise to debt constraints and the possibility of default. As discussed above, one of the models used at the ECB, the CMR model, does have an explicit banking sector and includes an agency problem with respect to the financing of investment by firms. As in most other DSGE models, the banking sector itself is, however, not subject to asymmetric information problems and costly financing constraints. As one of the major propagation mechanisms of the current financial crisis has been tensions in the interbank market, it is not surprising that a lot of current research focuses on modelling a more explicit banking sector. Recent examples are Gertler and Karadi (2009), Christensen and Dib (2009) and Gerali et al. (2009). It remains to be seen whether such extensions can capture the slow build-up of financial imbalances and associated credit and asset price booms that we have witnessed over the past decade and the sudden collapse in 2007 and 2008. Moving away from models that are linearised around a steady state is likely to be one condition for capturing such non-linear phenomena. Another feature that is often missing from DSGE models used in policy institutions is a well-developed housing market. Historical experience, as well as the current crisis, has highlighted the important role that overextended real estate markets play in many financial crisis. The work by Iacoviello (2004), which itself is based on Kiyotaki and Moore (1997) is one way of introducing financial frictions in real estate finance.

\section{Conclusion}

Bayesian DSGE models have become a useful tool in forecasting and policy analysis. They complement the many other tools such as BVARs, dynamic factor models, partial equilibrium models, small-scale indicator models that are frequently used in policy institutions. As these models are regularly used, there is a tendency to extend them to address more and more questions. This raises the issue of their optimal size. A single large model provides a common language that provides a benchmark for discussion amongst various economists. However, a large model may also be more difficult to understand and to handle and it may lack robustness. A suite of models on the other hand ensures robustness and flexibility in addressing the multitude of questions that typically come up in actual policy discussions. One of the practical challenges is to find a fine balance between those two approaches.

In this paper, we have compared the two main estimated DSGE models for the euro area used at the ECB: the NAWM and the CMR model. From a qualitative point of view, there is a broad agreement on the predictions they make, although, in quantitative terms, there are some differences. However, the perspectives provided by the two mod- 
els are often complementary, rather than conflicting. The role played by money, credit and, in general, financial factors in CMR complements the international dimension and the role of the exchange rate in the NAWM. This analysis shows the usefulness of carrying out policy exercises with alternative models in order to assess the robustness of the results.

Open Access This article is distributed under the terms of the Creative Commons Attribution Noncommercial License which permits any noncommercial use, distribution, and reproduction in any medium, provided the original author(s) and source are credited.

\section{References}

Bernanke B, Gertler M, Gilchrist S (1999) The financial accelerator in a quantitative business cycle framework. In: Taylor JB, Woodford M (eds) Handbook of macroeconomics. Elsevier Science, North-Holland, Amsterdam, New York, pp 1341-1393

Canova F, Sala L (2009) Back to square one: identification issues in DSGE models. J Monetary Econ 56(4):431-449

Chari VV, Christiano LJ, Eichenbaum M (1995) Inside money, outside money and short term interest rates. J Money Credit Banking 27:1354-1386

Chari VV, Kehoe P, McGrattan E (2008) New Keynesian models: not yet useful for policy analysis. NBER Working Paper 14313

Christensen I, Dib A (2009) Monetary policy in and estimated DSGE model with a financial accelerator. Working Paper 06-9, Bank of Canada

Christiano LJ, Eichenbaum M, Evans C (2005) Nominal rigidities and the dynamic effects of a shock to monetary policy. J Political Econ 113:1-45

Christiano LJ, Motto R, Rostagno M (2003) The great depression and the Friedman-Schwartz hypothesis. J Money Credit Banking 35(6, pt. 2):1119-1198

Christiano LJ, Motto R, Rostagno M (2007) Shocks, structures or policies? The Euro Area and the US After 2001. J Econ Dyn Control 32(8):2476-2506

Christoffel K, Coenen G, Warne A (2008) The new area-wide Model of the Euro Area: a micro-founded open-economy model for forecasting and policy analysis. ECB Working Paper 944

Collard F, Dellas H, Smets F (2009) Imperfect information and the business cycle. mimeo, University of Bern

Dieppe A, Pandiella AG, Willman A (2009) An estimated multi-country model simulated under rational expectations. ECB mimeo

Gali J (2009) The return of the Wage Phillips Curve. Working Paper, June 2009, CREI

Gerali A, Neri S, Sessa L, Signoretti F (2009) Credit and banking in a DSGE model of the Euro Area. Mimeo, Banca d'Italia

Gertler M, Karadi P (2009) A model of unconventional monetary policy. Mimeo

Gomes S, Jacquinot P, Pissani M (2009) EAGLE: a model for policy analysis of macroeconomic interdependence in the Euro Area, mimeo

Iacoviello M (2004) House prices, borrowing constraints and monetary policy. Am Econ Rev

Jacquinot P, Straub R (2008) Globalization and the euro area, simulation based analysis using the new area wide model. ECB Working paper 907

Kiyotaki N, Moore J (1997) Credit cycles. J Political Econ 105:211-248

Mackowiak B, Smets F (2009) Implications of micro price data for macro-economic models. In: Fuhrer J (ed) Understanding inflation and the implications for monetary policy: a Phillips curve retrospective, Conference held by the Federal Bank of Boston. MIT Press, Cambridge (in press)

McAdam P, Lombardo G (2009) Financial market frictions in a small open economy for the euro area, mimeo

Milani F (2006) A Bayesian DSGE model with infinite-horizon learning: do "mechanical" sources of persistence become superfluous? Int J Central Banking 2(3):87-106

Milani F (2008) Learning, monetary policy rules, and macroeconomic stability. J Econ Dyn Control 32(10):3148-3165 
Slobodyan S, Wouters R (2009) Estimating a medium-scale DSGE model with expectations based on small forecasting models, mimeo, National Bank of Belgium

Smets F, Wouters R (2003) An estimated dynamic stochastic general equilibrium model of the euro area. J Eur Econ Assoc 1(5):1123-1175

Smets F, Wouters R (2004) Forecasting with a Bayesian DSGE model: an application to the euro area. J Common Mark Stud 42(4):841-867

Smets F, Wouters R (2005) Bayesian new neoclassical synthesis models: modern tools for central banks. J Eur Econ Assoc 3(2-3):422-433

Smets F, Wouters R (2007) Shocks and frictions in US business cycles: a Bayesian DSGE approach. Am Econ Rev 97(3):586-606 